\begin{tabular}{|c|c|}
\hline 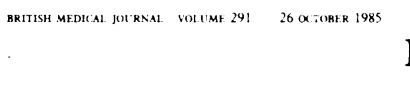 & PRACTICE OBSERVED \\
\hline \multicolumn{2}{|l|}{ Vocational Training } \\
\hline \multicolumn{2}{|c|}{$\begin{array}{l}\text { Multiple applications for vocational training rotations: can we } \\
\text { improve the system? }\end{array}$} \\
\hline \multicolumn{2}{|l|}{ PETER STOTT } \\
\hline $\begin{array}{l}\text { Abstract } \\
\text { Questionaires wert sen to } 392 \text { docton }\end{array}$ & 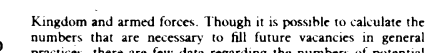 \\
\hline 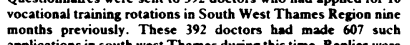 & 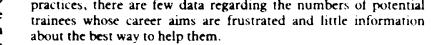 \\
\hline 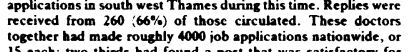 & 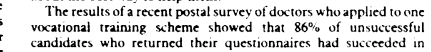 \\
\hline 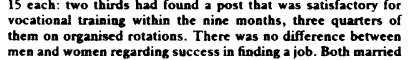 & 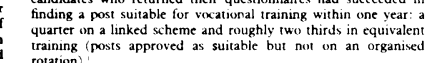 \\
\hline 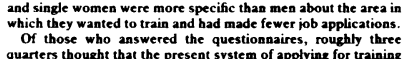 & 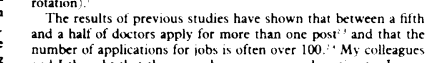 \\
\hline 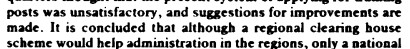 & 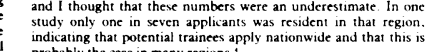 \\
\hline 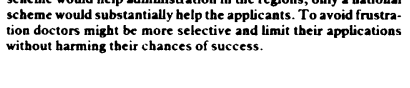 & 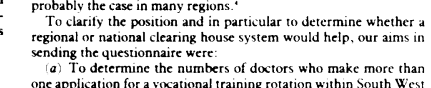 \\
\hline 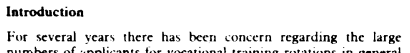 & 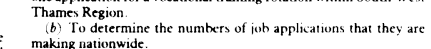 \\
\hline 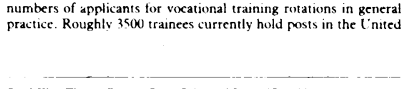 & 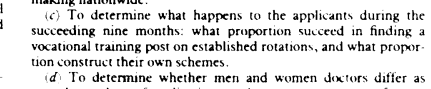 \\
\hline 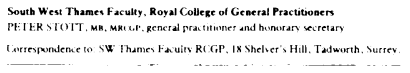 & 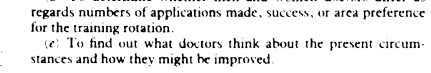 \\
\hline
\end{tabular}

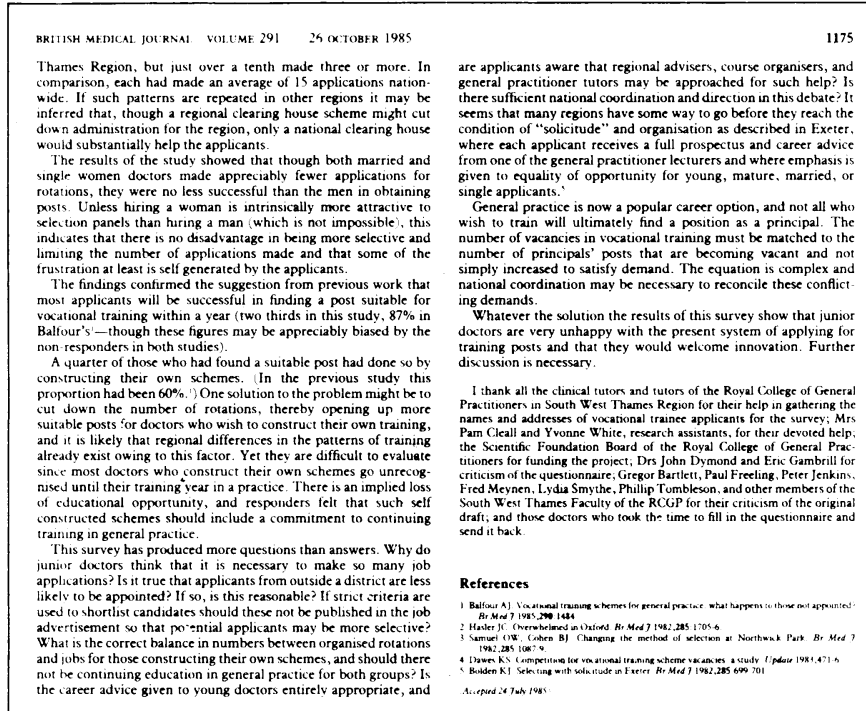

\title{
Practice Research
}

Open access radiology services: availability to general practitioners in the UK

G F MORGAN

Abstract

A postal survey was carried out among secretaries of local
medical committees to ascertain the availability of open access to medical committees to ascertain the avalability of open access to
radiology services in the United Kingom. The results from
different areas showed 2 wide variation of access, ranging from

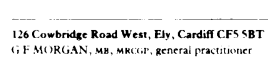

virtually none to complete access. General practitioner repre-
sentatives on management teams might encourage open access

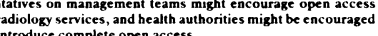

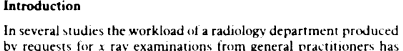
by requests for $x$ ray examinations from general practitioners has
been invertigated. "and estimates of the financial implications of

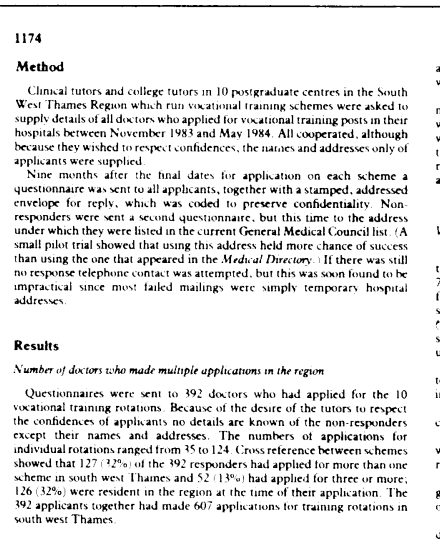

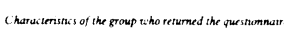

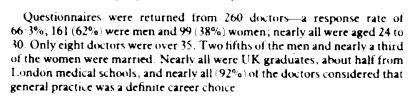

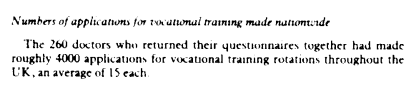

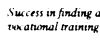

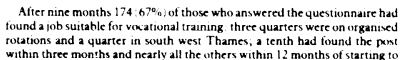

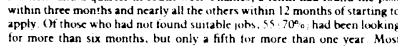

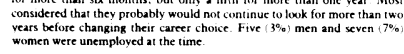

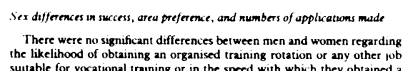

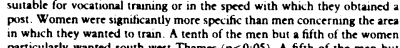

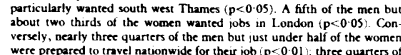

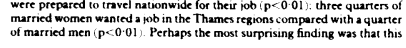

BRIIISH MEDICAL JOTRNAI VOLLME 291 26 (x.TOBER 1985

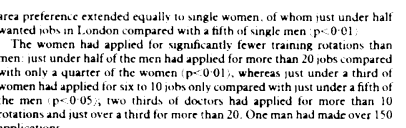

Viveus of the consumers

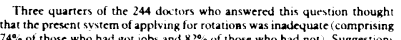

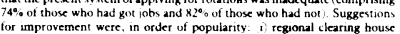

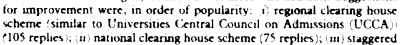

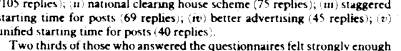

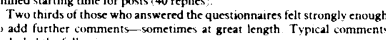

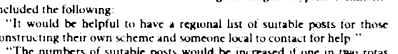

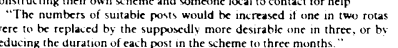

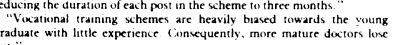

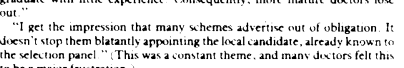

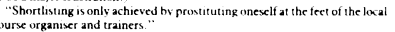

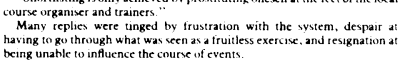

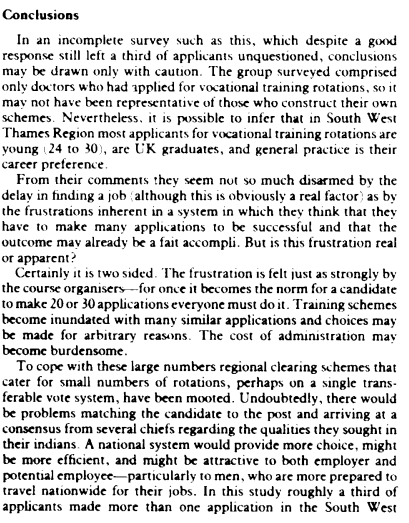

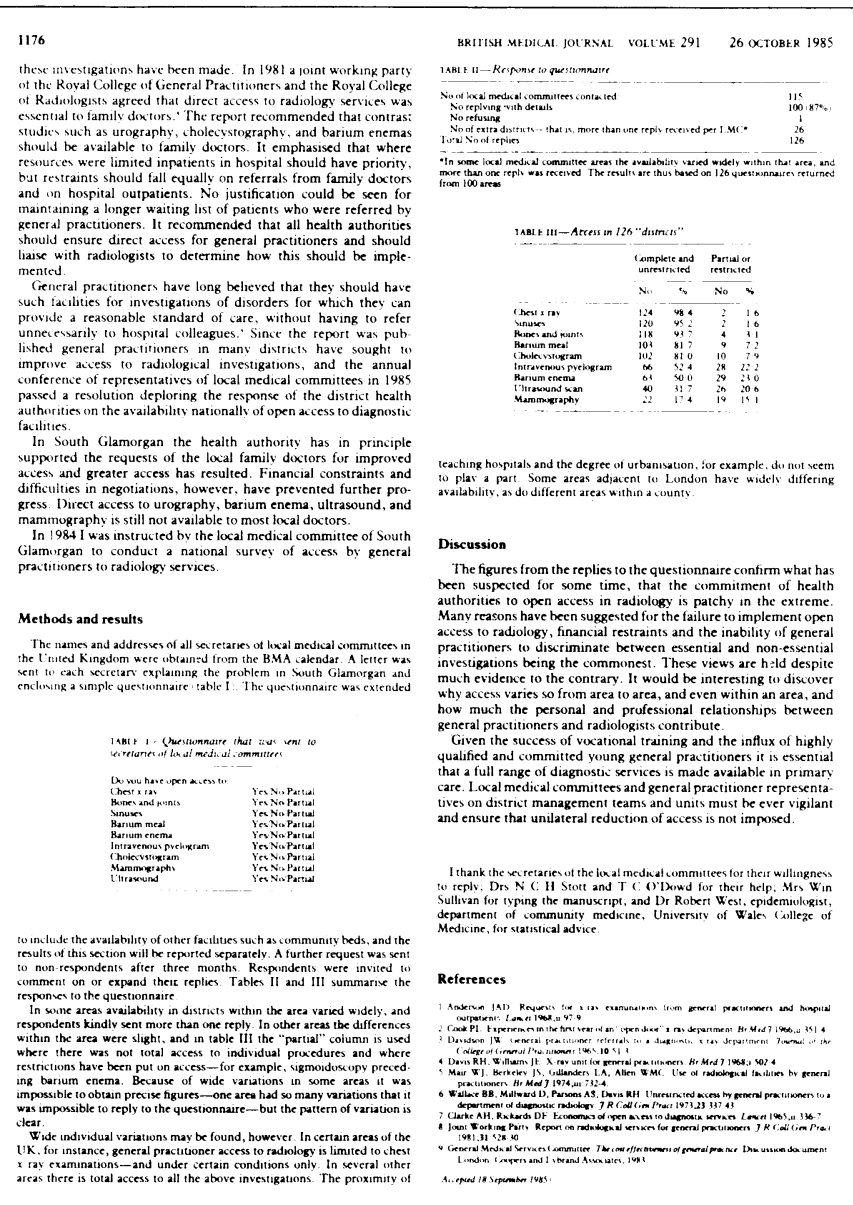

